\title{
Antagomirs Targeting MicroRNA-134 Increase Limk1 Levels After Experimental Seizures in Vitro and in Vivo
}

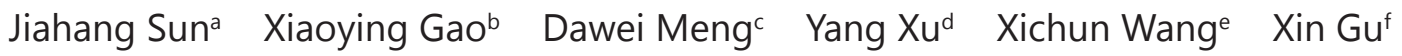 \\ Mian Guo ${ }^{\mathrm{a}}$ Xiaodong Shaog ${ }^{\mathrm{H}}$ Hongwen Yan ${ }^{\mathrm{h}}$ Chuanlu Jiang $^{\mathrm{a}} \quad$ Yongri Zheng $^{\mathrm{a}}$ \\ aDepartment of Neurosurgery, The Second Affiliated Hospital of Harbin Medical University, Harbin, \\ bDepartment of Anesthesiology, The Fourth Affiliated Hospital of Harbin Medical University, Harbin, \\ 'Department of Neurosurgery, Aviation General Hospital of China Medical University, Beijing, \\ dDepartment of Urology, Cancer Hospital of Harbin Medical University, Harbin, eDepartment of \\ Neurosurgery, Heilongjiang Provincial Hospital, Harbin, fDepartment of Head and Neck Surgery, Cancer \\ Hospital of Harbin Medical University, Harbin, ${ }^{9}$ School of Basic Medical Sciences, Harbin Medical \\ University, Harbin, hDepartment of Pediatric Hematology, Peking University International Hospital, \\ Beijing, People's Republic of China
}

\section{Key Words}

Epilepsy • MiR-134 • Limk1 • Cofilin • Hippocampus

\begin{abstract}
Background: MiR-134 is enriched in dendrites of hippocampal neurons and plays crucial roles in the progress of epilepsy. The present study aims to investigate the effects of antagomirs targeting miroRNA-134 (Ant-134) on limk1 expression and the binding of miR-134 and limk1 in experimental seizure. Methods: Status epilepticus (SE) rat model was established by lithium chloride-pilocarpine injection and was treated with Ant-134 by intracerebroventricular injection. Low $\mathrm{Mg}^{2+}$-exposed primary neurons were used as an in vitro model of SE. The expression of miR-134 was determined using real-time PCR. Protein expressions of limk1 and cofilin were determined by Western blotting. Luciferase reporter assay was used to examine the binding between miR-134 and limk1 3'-untranslated region. Results: The expression of miR-134 was markedly enhanced in hippocampus of the SE rats and low $\mathrm{Mg}^{2+}$-exposed neurons. Ant-134 increased the expression of limk1 and reduced the expression of cofilin in the SE hippocampus and Low $\mathrm{Mg}^{2+}$-exposed neurons. In addition, luciferase reporter assay confirmed that miR-134 bound limk1 3'-UTR. MiR-134 overexpression inhibited limk1 mRNA and protein expressions in neurons. Conclusion: Blockage of miR-134 upregulates limk1 expression and downregulated cofilin expression in hippocampus of the SE rats. This mechanism may contribute to the neuroprotective effects of Ant-134.

J. Sun and X. Gao are contributed equally to this work.

Dr. Yongri Zheng,

and Dr. Chuanlu Jiang

Department of Neurosurgery, The Second Affiliated Hospital of Harbin Medical University, 246 Xuefu Road, Harbin (People's Republic of China)

Tel. +86-451-86605034, E-Mail jiangchuanlu993@163.com/zhengyongri2000@163.com
\end{abstract}




\section{Cellular Physiology Cell Physiol Biochem 2017;43:636-643

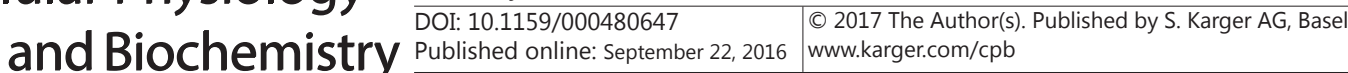 \\ Sun et al:: Ant-134 Upregulates limk1 in SE}

\section{Introduction}

Epilepsy is a serious neurological disorder which is characterized by recurrent spontaneous seizures. Temporal lobe epilepsy (TLE) is the most common type of epilepsy [1]. Patients with TLE suffer from consciousness and memory impairment [2] and psychosocial difficulties [3]. Epilepsy surgery and antiepileptic drugs are the major treatments for epileptic disorders [4]. However, both methods have side effects such as nausea, drowsiness, headache, dizziness, and ataxia [5]. In addition, approximately one-third of patients with epilepsy suffer from drug-resistant and continue to have seizures. Thus, to further reveal the pathological mechanisms of epilepsy and develop novel therapeutic strategies is beneficial for epilepsy treatment.

MicroRNAs are a class of small ( $\sim 22 \mathrm{nt}$ ), endogenously expressed noncoding RNAs which post-transcriptionally regulate the expression of protein-coding mRNAs by interacting with the 3' untranslated region (UTR) of these mRNAs [6, 7]. MicroRNAs are enriched in the central nervous system (CNS), where they are crucial for developments and physiological processes [8]. Thus, deficiency or dysfunction of microRNAs may lead to corresponding disorders in the CNS [9]. Since Nudelman and colleagues first reported the expression of miR132 in the hippocampus of pilocarpine-induced status epilepticus (SE) mice [10], numerous microRNAs were found to be associated with the initiation and development of epilepsy [11, 12]. MiR-134 is localized in neuronal dendrites and negatively regulates the size of dendritic spines [13]. In accordance with its physiological location, miR-134 has been found to be associated with the learning and memory $[14,15]$. In epileptic mice, miR-134 was found to be increased in hippocampal CA1 region. Antagomir-mediated silencing of miR-134 could reduce pyramidal neuron spine density and suppress the seizure [16].

Limk1 is a member of the LIM kinase family which act as serine/threonine kinases and play a crucial role in actin dynamics [17]. Limk1 regulates actin through phosphorylating and inactivating cofilin, the latter catalyzes actin polymerization and depolymerization [18]. Limk1 knockout mice exhibit significant abnormalities in spine morphology and in synaptic functions [19]. Previous studies have demonstrated that limk1 is associated with synaptic plasticity and could regulate cognitive functions [20-22]. In hippocampal neurons, miR-134 binds limk1 mRNA and inhibits its protein expression [13]. In TLE patients and rat models, the protein expression of limk1 was found to be altered in hippocampus [23]. In the present study, we treated the SE rats with antagomirs targeting miroRNA-134 (Ant-134) and evaluated the effects of Ant-134 on limk1 expression in experimental seizures models in vivo and in vitro.

\section{Materials and Methods}

\section{Experimental groups}

Male Sprague-Dawley (SD) rats (180-220 g) (Experimental Animal Centre of the Second Affiliated Hospital of Harbin Medical University, Harbin, China) were randomly assigned into 4 groups: control group (Con, $n=6$ ), status epilepticus group ( $\mathrm{SE}, \mathrm{n}=6)$ ), SE treated with scramble antagomirs sequence group (SE+Scr, $\mathrm{n}=6$ ), and SE treated with antagomirs targeting miR-134 group (SE+Ant-134, n=6). The rats were housed in humidity (50-60\%) and were kept on a 12-h light/dark cycle with free access to standard rodent food and water. Protocols and procedures were approved by the Ethics Committee of The Second Affiliated Hospital of Harbin Medical University.

\section{SE induction}

The rats in the SE, SE+Scr and SE+Ant-134 groups received an intraperitoneal injection of $125 \mathrm{mg} /$ $\mathrm{kg}$ lithium chloride (LiCl, Sigma, St. Louis, MO) and followed by an intraperitoneal injection of $20 \mathrm{mg} /$ $\mathrm{kg}$ pilocarpine hydrochloride (Sigma) 18-20 h later. Half an hour prior to the pilocarpine treatment, the rats received an intraperitoneal injection of $1 \mathrm{mg} / \mathrm{kg}$ Scopolamine methyl bromide (Sigma) to reduce the peripheral cholinergic effects of pilocarpine. The rats in the Con group received an equal volume of saline. 


\section{Cellular Physiology Cell Physiol Biochem 2017;43:636-643

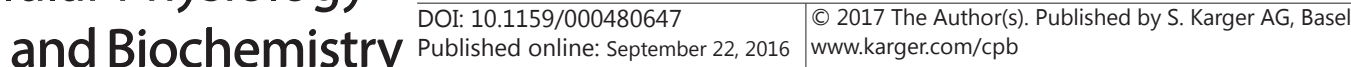

Sun et al.: Ant-134 Upregulates limk1 in SE

Behavioral changes of the rats were graded according to Racine's classification [24]. Those rats in which seizure severity reached to stage IV or V were used in the experiment. Diazepam $10 \mathrm{mg} / \mathrm{kg}$ (Sigma) was administered intraperitoneally to SE rats $90 \mathrm{~min}$ after the onset of SE to control the seizure activity [25].

\section{Ant-134 treatment}

Immediately after the SE was controlled by diazepam administration, the rats were anesthetized with $30 \mathrm{mg} / \mathrm{kg}$ sodium pentobarbital and placed in a stereotaxic frame. The rats were inserted with a 23-gauged stainless-steel guide cannula into the bilateral ventricle through a hole drilled through the skull $4.4 \mathrm{~mm}$ below the top of the skull, $1.5 \mathrm{~mm}$ lateral and $0.8 \mathrm{~mm}$ posterior to the bregma. Rats received a $2 \mu \mathrm{L}$ infusion of $0.12 \mathrm{nM}$ antagomirs targeting miR-134 (Ant-134: 5'- $\mathrm{C}_{\mathrm{ps}} \mathrm{C}_{\mathrm{ps}}$ CCUCUGGUCAACCAGUC $\mathrm{ps}_{\mathrm{ps}} \mathrm{C}_{\mathrm{ps}} \mathrm{A}_{\mathrm{ps}}$-Chol-3') or a non-targeting scrambled version of the antagomir (Scr: $5^{\prime}-\mathrm{C}_{\mathrm{ps}} \mathrm{A}_{\mathrm{ps}}$ GUACUUUUGUGUAGUA $\mathrm{ps}_{\mathrm{ps}} \mathrm{A}_{\mathrm{ps}} \mathrm{A}_{\mathrm{ps}}-\mathrm{Chol}^{\prime} 3^{\prime}$ ) (full length nucleotide 2'-methoxy modification, GenePharma, Shanghai, China) in artificial cerebrospinal fluid at a speed of $0.2 \mu \mathrm{L} / \mathrm{min}$. The cannula was remained in the brain for additional $10 \mathrm{~min}$. All the rats were sacrificed at day 3 for biological analyses.

\section{Primary neuron culture}

Twenty-four hours postnatal SD rat pups were obtained from the Experimental Animal Centre of the Second Affiliated Hospital of Harbin Medical University (Harbin, China). The brain were separated and dissociated in trypsin for $30 \mathrm{~min}$ at $37^{\circ} \mathrm{C}$. The dissociated tissues were centrifuged at $500 \mathrm{~g} / \mathrm{min}$ for 10 min and the supernatant was removed. The tissues were mechanically dissociated in phosphate buffered saline (PBS) and centrifuged at $150 \mathrm{~g} / \mathrm{min}$ for $10 \mathrm{~min}$. Following the debris was eliminated, the cells were resuspended with Dulbecco's Modified Eagle's Medium (DMEM, Gibco Life Technologies, Carlsbad, CA, USA) and filtered through a strainer (300/400 mesh) to remove the undigested tissues. The neurons were resuspended in DMEM supplemented with $10 \% \mathrm{FBS}$ and seeded at $1 \times 10^{5}$ cells $/ \mathrm{ml}$ onto poly-D-lysine-coated 12 well plates. Neurons were maintained at $37^{\circ} \mathrm{C}$ in a $5 \% \mathrm{CO}_{2} / 95 \%$ air atmosphere and the medium was half-replaced every 3 days. 5-Fluorouracil (5-FU, Sigma) was used for glial cells elimination.

\section{Cell transfection and low $\mathrm{Mg}^{2+}$ treatment}

The neurons at day 6 were transfected with miR-134 antagomirs, miR-134 mimics, or the negative controls (GenePharma, Shanghai, China) using lipofectamine 3000 transfection reagent (Invitrogen, Carlsbad, CA, USA) according to the manufacturer's protocol. Two days after transfection, the transfection efficiency was detected by real-time PCR and the cells transfected with miR-134 antagomirs or not were exposed to $\mathrm{Mg}^{2+}$-free D-Hank's solution (Solarbio) for $3 \mathrm{~h}$.

\section{Limk1 3'UTR luciferase reporter assay}

HEK 293T (human embryonic kidney) cells were obtained from the Type Culture Collection of Chinese Academy of Sciences (Shanghai, China). The cells were maintained in DMEM with $10 \% \mathrm{FBS}$ at $37^{\circ} \mathrm{C}$ in a humidified $5 \% \mathrm{CO}_{2}$ incubator. HEK $293 \mathrm{~T}$ cells were plated at $1.0 \times 10^{6}$ cells per well in 12 -well dishes. MiR134 mimics or miR-negative control and pmirGLO-limk1 3'UTR vector were co-transfected into cells using lipofectamine 3000 (Invitrogen). Luciferase activities were detected with a Dual-Luciferase Reporter Assay Kit (Promega, Fitchburg, WI, USA) according to the manufacturer's protocol. The absorbance of Firefly and Renilla luciferase activity was detected by a Microplate Luminometer (Berthold Technologies, Bad Wildbad, Germany).

\section{RNA extraction and real-time PCR}

Total RNA from the hippocampal tissues and the primary neurons were isolated using a Total RNA Extraction kit (BioTeke Corporation, Beijing, China), according to the manufacturer's

Table 1. Sequences of primers

\begin{tabular}{lccc}
\hline Genes & Sequence F(5'-3') & Sequence R(5'-3') & Size (bp) \\
\hline miR-134 & GACTGGCTGTGACTGGTTGACC & GTGCAGGGTCCGAGGTATTC & 63 \\
U6 & CTCGCTTCGGCAGCACA & AACGCTTCACGAATTTGCGT & 94 \\
limk1 & ACAGTCACCCTCGTGTCTATCC & TCTCGTCCAGCGGCACATT & 232 \\
$\beta$-actin & GGAGATTACTGCCCTGGCTCCTAGC & GGCCGGACTCATCGTACTCCTGCTT & 155 \\
\hline
\end{tabular}


protocol, and then reverse transcribed into cDNA with the oligonucleotide primer and super M-MLV (BioTeke, Beijing, China). Real-time PCR was performed using $2 \times$ Power Taq PCR Master Mix (BioTeke), SYBR Green (Solarbio) and primers (Table 1) on an Exicycler 96 (Bioneer, Daejeon, Korea). The mRNA levels were normalized against $\mathrm{U} 6$ or $\beta$-actin and presented as $2^{-\Delta \Delta c t}$.

\section{Western blotting analysis}

The hippocampal tissues and primary neurons were lysed in cooled RIPA buffer supplemented with phenylmethanesulfonyl fluoride and the homogenous were centrifuged at $12,000 \mathrm{~g}$ for $10 \mathrm{~min}$ at $4^{\circ} \mathrm{C}$. The supernatant was collected and followed by protein concentration determination using a BCA Assay kit (Beyotime). After boiled in loading buffer, protein samples were electrophoresed on $10 \%$ sodium dodecyl sulfate polyacrylamide (SDS-PAGE) gels and subsequently transferred to polyvinylidene difluoride membranes (Millipore, Bedford, MA, USA). The membranes were blocked with $5 \%$ non-fat milk in Tris buffered saline with Tween-20 (TBST) at room temperature for $1 \mathrm{~h}$ and probed with primary anti-limk1 antibody (1:1000), anti-cofilin antibody (1:500, Sango biotech) and anti- $\beta$-actin antibody (1:1000, Santa Cruz Biotechnology, Santa Cruz, CA) at $4^{\circ} \mathrm{C}$ overnight. After a wash stage with TBST, the membranes were incubated with horseradish peroxidase-conjugated anti-rabbit or anti-mouse secondary antibody (Beyotime) at $37^{\circ} \mathrm{C}$ for $45 \mathrm{~min}$. The membranes were then developed using the ECL reagent (7 Sea Pharmtech, Shanghai, China) and visualized with autoradiography film. The intensity of each band was quantified using Gel-Pro-Analyzer software (Media Cybernetics, Bethesda, MD).

\section{Statistical analysis}

Data are expressed as mean \pm SD. Multiple comparisons were analyzed by one-way ANOVA, followed by LSD test. At least three independent experiments were carried out. $P<0.05$ was considered statistically significant.

\section{Results}

\section{Ant-134 increased limk1 expression in the hippocampus of SE rats}

In the hippocampus of SE rats, the expression of miR-134 was significantly upregulated compared with that in the control rats (Fig. 1A). In line with this finding, the protein expression of limk1 was markedly downregulated and that of cofilin was upregulated in the

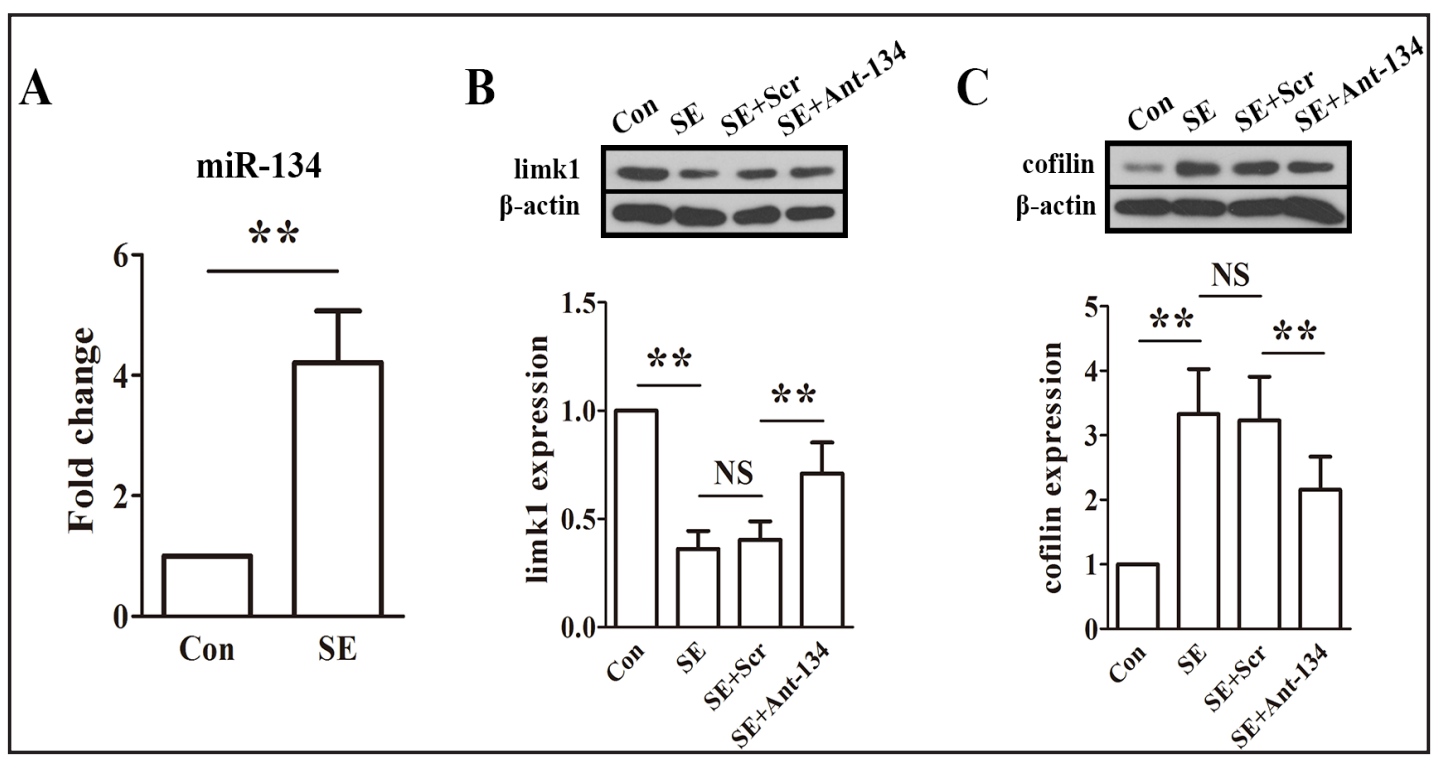

Fig. 1. MiR-134 antagomirs upregulated limk1 expression and downregulated cofilin expression in the hippocampus of the SE rats. The expression of miR-134 was upregulated in hippocampus of the SE rats (A). Ant-134 restored the downregulation of limk1 protein expression (B) and the upregulation of cofilin protein expression (C) in hippocampus of the SE rats. Data are mean $\pm S D, n=6$. ${ }^{* *} \mathrm{P}<0.01$, NS $\mathrm{P}>0.05$. 


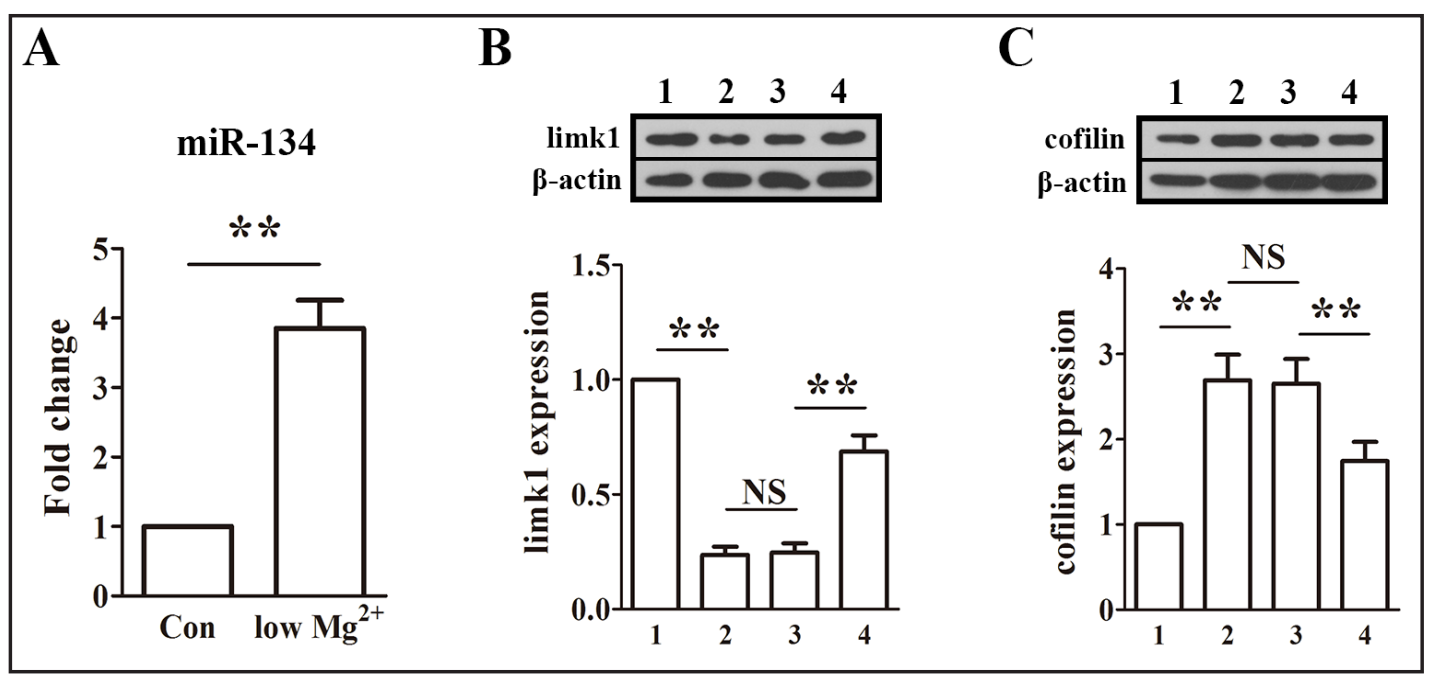

Fig. 2. MiR-134 antagomirs upregulated limk1 expression and downregulated cofilin expression in the low $\mathrm{Mg}^{2+}$-exposed neurons. The expression of miR-134 was upregulated in the low $\mathrm{Mg}^{2+}$-exposed neurons (A). Ant-134 restored the downregulation of limk1 protein expression (B) and the upregulation of cofilin protein expression $(\mathrm{C})$ in the low $\mathrm{Mg}^{2+}$-exposed neurons. Data are mean $\pm \mathrm{SD}, \mathrm{n}=6 .{ }^{* *} \mathrm{P}<0.01, \mathrm{NS} \mathrm{P}>0.05$. 1 : Con, 2: low $\mathrm{Mg}^{2+}, 3$ : low $\mathrm{Mg}^{2+}+\mathrm{Scr}, 4$ : low $\mathrm{Mg}^{2+}+$ Ant-134.

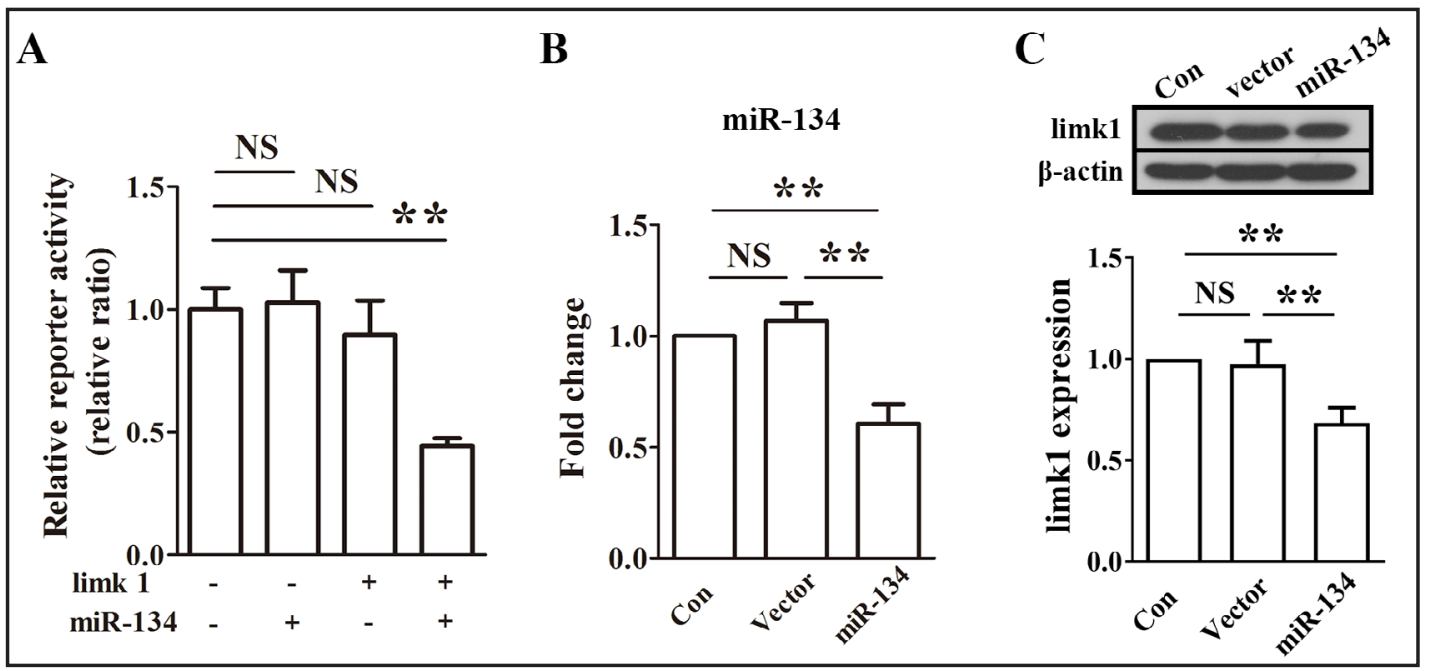

Fig. 3. MiR-134 bound limk1 and inhibited limk1 expression. Results of luciferase reporter assay showed that miR-134 binds to limk13'UTR (A). Overexpression of miR-134 in primary neurons induced downregulation of mRNA (E) and protein (F) expression of limk1. Data are mean $\pm \mathrm{SD}, \mathrm{n}=3$. ${ }^{* *} \mathrm{P}<0.01, \mathrm{NS} \mathrm{P}>0.05$.

hippocampus of SE rats ( $P<0.01$ vs. control rats, Fig. 1B, C). After intracerebroventricular injections of Ant-134, the protein expression of limk1 was significantly enhanced and that of cofilin was diminished in the hippocampus.

\section{Ant-134 increased limk1 expression in the primary neurons}

Low $\mathrm{Mg}^{2+}$ medium results in SE-like electrographic activities in primary cultured neurons [26]. In agreement with the in vivo study, we found that low $\mathrm{Mg}^{2+}$ medium induced dramatically increased expression of miR-134 in neurons compared with the control neurons (Fig. 2A). In addition, markedly lower expression of limk1 and higher expression of cofilin were found in the low- $\mathrm{Mg}^{2+}$-cultured neurons (Fig. 2B and C). Ant-134 transfection restored these changes. 


\section{Cellular Physiology Cell Physiol Biochem 2017;43:636-643

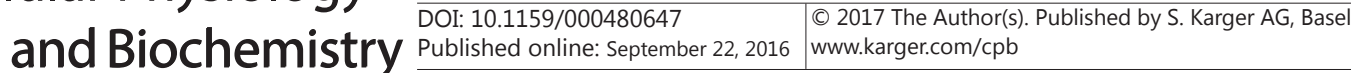 \\ Sun et al:: Ant-134 Upregulates limk1 in SE}

MiR-134 targets limk1 and inhibits its expression

The interaction between limk1 and miR-134 was examined using luciferase reporter assay. The reporter activity was significantly decreased when miR-134 mimics and limk1 3'UTR were co-transfected into the cells (Fig. 3A). The results confirmed that miR-134 bound the 3'-UTR of limk1 mRNA. Furthermore, exogenous miR-134 induced significantly downregulation of limk1 mRNA and protein expressions in cultured neurons (Fig. 3B and C).

\section{Discussion}

In the present study, we found that Ant-134 mediated blockage of miR-134 decreased limk1 expression and increased cofilin expression in the hippocampus of SE rats and in cultured low $\mathrm{Mg}^{2+}$-induced neurons. In addition, we confirmed that miR-134 bound limk1 and found that miR-134 transfection inhibited limk1 expression in neurons.

In the animal study, we treated the rats with Ant-134 after the model establishment, which is different from the method used in the previous study [27]. Here we aimed to evaluate the treatment effect of Ant-134 instead of the preventive effect. Although the rats received antagomirs under sedation, we did not find abnormal reactions in the rats and the results were in agreement with that in the pretreatment study.

Compelling data implicate the roles of miRNAs in the pathological processes of epilepsy $[28,29]$. MiR-134 was found to be expressed in neurons in the brain and localized in dendrites. Increased miR-134 levels have been found in hippocampus of TLE patients and pentylenetetrazol-induced mice [30]. Previous work showed that silencing of miR-134 exhibited neuroprotective effects and reduces status epilepticus in vivo [16]. In the present study, miR-134 was found to be upregulated in the hippocampus of epileptic rats induced by LiCl-pilocarpine and in cultured neurons exposed to low $\mathrm{Mg}^{2+}$ medium, which was consistent with the previous studies [26, 27]. Limk1 is a target gene of miR-134. Huang et al. reported that the expression of limk1 was increased in the hippocampus of patients and rats with TLE [23]. However, in the current study, we found that limk1 expression was downregulated and cofilin expression was upregulated in the hippocampus of epileptic rats. Interestingly, Wang et al. found that limk1 was downregulated in low $\mathrm{Mg}^{2+}$-induced neurons [26], which was in agreement with our in vitro study. The results Huang and colleagues obtained from TLE rats and patients were consistent. The finding of downregulated limk1 in our study consisted with the upregulated miR-134. The discrepancy between our and Huang's study may need to be further studied.

We found that Ant-134 treatment induced increased expression of limk1 and decreased expression of cofilin, which indicated that Ant-134 blocked the binding of miR-134 and limk1, restored the transcription of limk1 and suppressed the expression of cofilin. Synaptic actin dynamics, which is controlled by limk1 through cofilin, plays an important role in learning behavior and postsynaptic receptor availability [19, 31]. Hence, regulation of limk 1 and cofilin may be beneficial for learning improvement. Together with the data in our study, the effect of Ant-134 on the regulation of limk1 and cofilin expressions may be associated with its neuroprotective effects. Unfortunately, the present study did not directly improve whether limk1 or cofilin affected the initiation or development of epilepsy, which will be studied in future.

In conclusion, miR-134 antagomirs binds limk1 and inhibits its expression, thereby decreasing cofilin protein expression in the hippocampus of LiCl-pilocarpine-induced epileptic rats. This mechanism may contribute to the neuroprotective effects of Ant-134.

\section{Acknowledgements}

This study was supported by grants from the National Natural Science Foundation of China (No. 81401087), the Natural Science Foundation of Heilongjiang Province (No. QC2014C099), and the Post-doctoral Foundation of Heilongjiang Province (No. LBH-Z16106). 


\section{Cellular Physiology Cell Physiol Biochem 2017;43:636-643

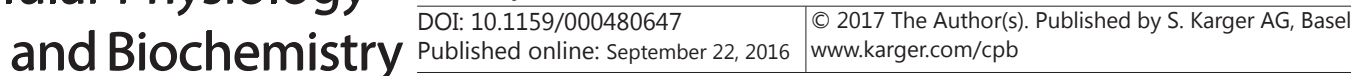

Sun et al.: Ant-134 Upregulates limk1 in SE

\section{Disclosure Statement}

The authors declare no conflict of interest.

\section{References}

$>1$ Bertram EH: Temporal lobe epilepsy: where do the seizures really begin? Epilepsy Behav 2009;14 Suppl 1:32-37.

-2 Rzezak P, Lima EM, Gargaro AC, Coimbra E, de Vincentiis S, Velasco TR, Leite JP, Busatto GF, Valente KD: Everyday memory impairment in patients with temporal lobe epilepsy caused by hippocampal sclerosis. Epilepsy Behav 2017;69:31-36.

3 Bora E, Meletti S: Social cognition in temporal lobe epilepsy: A systematic review and meta-analysis. Epilepsy Behav 2016;60:50-57.

4 Kawai K: Epilepsy surgery: current status and ongoing challenges. Neurol Med Chir (Tokyo) 2015;55:357366.

5 Brodie MJ, Dichter MA: Antiepileptic drugs. N Engl J Med 1996;334:168-175.

6 Bartel DP: MicroRNAs: genomics, biogenesis, mechanism, and function. Cell 2004;116:281-297.

7 Ambros V: The functions of animal microRNAs. Nature 2004;431:350-355.

8 Kosik KS: The neuronal microRNA system. Nat Rev Neurosci 2006;7:911-920.

-9 Im HI, Kenny PJ: MicroRNAs in neuronal function and dysfunction. Trends Neurosci 2012;35:325-334.

10 Nudelman AS, DiRocco DP, Lambert TJ, Garelick MG, Le J, Nathanson NM, Storm DR: Neuronal activity rapidly induces transcription of the CREB-regulated microRNA-132, in vivo. Hippocampus 2010;20:492498.

11 Brennan GP, Henshall DC: microRNAs in the pathophysiology of epilepsy. Neurosci Lett 2017;10.1016/j. neulet.2017.01.017

12 Henshall DC, Hamer HM, Pasterkamp RJ, Goldstein DB, Kjems J, Prehn JH, Schorge S, Lamottke K, Rosenow F: MicroRNAs in epilepsy: pathophysiology and clinical utility. Lancet Neurol 2016;15:1368-1376.

$>13$ Schratt GM, Tuebing F, Nigh EA, Kane CG, Sabatini ME, Kiebler M, Greenberg ME: A brain-specific microRNA regulates dendritic spine development. Nature 2006;439:283-289.

14 Gao J, Wang WY, Mao YW, Graff J, Guan JS, Pan L, Mak G, Kim D, Su SC, Tsai LH: A novel pathway regulates memory and plasticity via SIRT1 and miR-134. Nature 2010;466:1105-1109.

15 Christensen M, Larsen LA, Kauppinen S, Schratt G: Recombinant Adeno-Associated Virus-Mediated microRNA Delivery into the Postnatal Mouse Brain Reveals a Role for miR-134 in Dendritogenesis in vivo. Front Neural Circuits 2010;3:16.

16 Jimenez-Mateos EM, Engel T, Merino-Serrais P, McKiernan RC, Tanaka K, Mouri G, Sano T, O’Tuathaigh C, Waddington JL, Prenter S, Delanty N, Farrell MA, O’Brien DF, Conroy RM, Stallings RL, DeFelipe J, Henshall DC: Silencing microRNA-134 produces neuroprotective and prolonged seizure-suppressive effects. Nat Med 2012;18:1087-1094.

17 Gorovoy M, Niu J, Bernard O, Profirovic J, Minshall R, Neamu R, Voyno-Yasenetskaya T: LIM kinase 1 coordinates microtubule stability and actin polymerization in human endothelial cells. J Biol Chem 2005;280:26533-26542.

18 Bravo-Cordero JJ, Magalhaes MA, Eddy RJ, Hodgson L, Condeelis J: Functions of cofilin in cell locomotion and invasion. Nat Rev Mol Cell Biol 2013;14:405-415.

19 Meng Y, Zhang Y, Tregoubov V, Janus C, Cruz L, Jackson M, Lu WY, MacDonald JF, Wang JY, Falls DL, Jia Z: Abnormal spine morphology and enhanced LTP in LIMK-1 knockout mice. Neuron 2002;35:121-133.

20 Yu Y, Zhang P, Yan J, Sun Y, Wu X, Xi S, Zhang L, Sun Y, Hu R, Jiang H: Sevoflurane induces cognitive impairments via the MiR-27b/LIMK1-signaling pathway in developing rats. Inhal Toxicol 2016;28:731-738.

21 Liu A, Zhou Z, Dang R, Zhu Y, Qi J, He G, Leung C, Pak D, Jia Z, Xie W: Neuroligin 1 regulates spines and synaptic plasticity via LIMK1/cofilin-mediated actin reorganization. J Cell Biol 2016;212:449-463.

22 Todorovski Z, Asrar S, Liu J, Saw NM, Joshi K, Cortez MA, Snead OC, 3rd, Xie W, Jia Z: LIMK1 regulates longterm memory and synaptic plasticity via the transcriptional factor CREB. Mol Cell Biol 2015;35:1316-1328. 


\section{Cellular Physiology Cell Physiol Biochem 2017;43:636-643

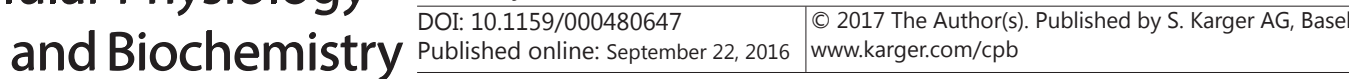 \\ Sun et al.: Ant-134 Upregulates limk1 in SE}

23 Huang H, Wang H, Yuan J, Wu X, Huang Y, Zhou X, Chen Y: Protein expression of phospho-lim kinase-1 in patients and an experimental rat model with intractable temporal lobe epilepsy. Int J Clin Exp Med 2015;8:625-633.

24 Racine RJ: Modification of seizure activity by electrical stimulation. II. Motor seizure. Electroencephalogr Clin Neurophysiol 1972;32:281-294.

25 Ashhab MU, Omran A, Kong H, Gan N, He F, Peng J, Yin F: Expressions of tumor necrosis factor alpha and microRNA-155 in immature rat model of status epilepticus and children with mesial temporal lobe epilepsy. J Mol Neurosci 2013;51:950-958.

-26 Wang XM, Jia RH, Wei D, Cui WY, Jiang W: MiR-134 blockade prevents status epilepticus like-activity and is neuroprotective in cultured hippocampal neurons. Neurosci Lett 2014;572:20-25.

27 Jimenez-Mateos EM, Engel T, Merino-Serrais P, Fernaud-Espinosa I, Rodriguez-Alvarez N, Reynolds J, Reschke CR, Conroy RM, McKiernan RC, deFelipe J, Henshall DC: Antagomirs targeting microRNA-134 increase hippocampal pyramidal neuron spine volume in vivo and protect against pilocarpine-induced status epilepticus. Brain Struct Funct 2015;220:2387-2399.

-28 Jimenez-Mateos EM, Henshall DC: Epilepsy and microRNA. Neuroscience 2013;238:218-229.

-29 Dogini DB, Avansini SH, Vieira AS, Lopes-Cendes I: MicroRNA regulation and dysregulation in epilepsy. Front Cell Neurosci 2013;7:172.

-30 Reschke CR, Silva LF, Norwood BA, Senthilkumar K, Morris G, Sanz-Rodriguez A, Conroy RM, Costard L, Neubert V, Bauer S, Farrell MA, O’Brien DF, Delanty N, Schorge S, Pasterkamp RJ, Rosenow F, Henshall DC: Potent Anti-seizure Effects of Locked Nucleic Acid Antagomirs Targeting miR-134 in Multiple Mouse and Rat Models of Epilepsy. Mol Ther Nucleic Acids 2017;6:45-56.

-31 Rust MB, Gurniak CB, Renner M, Vara H, Morando L, Gorlich A, Sassoe-Pognetto M, Banchaabouchi MA, Giustetto M, Triller A, Choquet D, Witke W: Learning, AMPA receptor mobility and synaptic plasticity depend on n-cofilin-mediated actin dynamics. EMBO J 2010;29:1889-1902. 